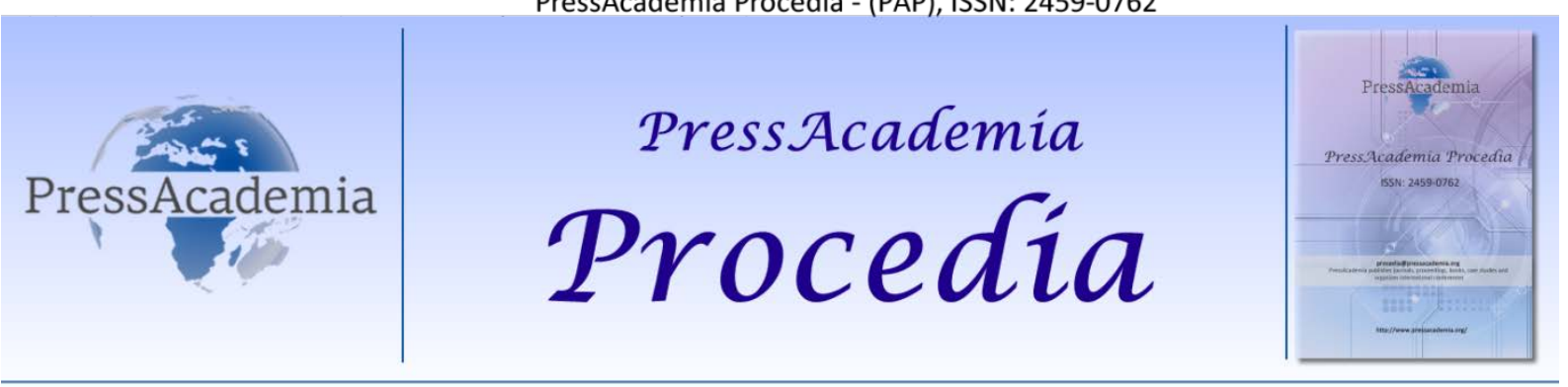

Global Business ResearchCongress (GBRC), May 26-27, 2016, Istanbul, Turkey.

\title{
CULTURAL SENSITIVITY AND COMMUNICATION SKILLS ON THE RELATIONSHIP BETWEEN AN INVESTIGATION
}

\section{DOI: 10.17261/Pressacademia.2016118665}

\section{Nuray Mercan}

${ }^{1}$ Dumlupınar Üniversitesi, nuraymercan26@gmail.com

\begin{abstract}
Intercultural awareness, the evaluation and the identification of cultural diversity requires the development of appropriate and effective behavior. Intercultural communication between cultures in terms of sensitivity is defined as the ability to develop positive emotions. Cases of intercultural communication, a call for intercultural dialogue beyond the vineyard belonging to different cultures and to address the communication and interaction patterns can be said to have host. People who participated in the communication, knows communication behavior of expression, as long as individuals belonging to a different culture, attitude and behavior will be based on their own cultural norms. The purpose of this study is to examine whether there is a relationship between the employees in the hospitality business communication skills and intercultural sensitivity. Research method was used for the survey technique. Located in the universe of the study Edremit Bay Tourism Operations Certificate hotels, hotels certified by the Municipality constitutes enterprises. Way of understanding different cultures and develop intercultural sensitivity is a need to improve communication skills. The aim of this study reveals differences in different cultures and intercultural communication sensitivity How? How to set up a communication bridge between cultures? It is to seek answers to their questions. Things correlation analysis; mental their communication skills, emotional and behavioral dimensions of the intercultural sensitivity interaction of the size of the responsibility to communicate the dimension of responsibility, respect for cultural differences, self-confidence in communication, was found to be positively correlated with caution that size to communicate the enjoyment and communication.
\end{abstract}

Keywords : Different cultures, intercultural awareness, communication

JEL Codes : M10,M11

\section{KÜLTÜRLER ARASI DUYARLILIK VE ILETiŞiM BECERILERI ARASINDAKi íLiŞKi ÜZERINE BíR ARAŞTIRMA}

\section{ÖZET}

Kültürlerarası duyarlıık, kültürel farklııkların tanımlanmasında ve değerlendirilmesinde uygun ve etkili davranış geliştirmeyi gerektirmektedir. Kültürlerarası iletişim açısından kültürler arası duyarlılık pozitif duygu geliştirebilme yeteneği olarak tanımlanmaktadır. Kültürlerarası iletişim olgusunun, farklı kültür ve aidiyet bağlarının iletişim ve etkileşim örüntülerini ele almasının ötesinde kültürlerarası diyaloğa yönelik bir çağrıyı barındırdığı da söylenebilmektedir. Iletişime katılan kişiler, farklı bir kültüre mensup bireylerin iletişim davranışlarını bilmediği sürece ifadeleri, tutum ve davranışları kendi kültürel normlarına dayalı olacaktır. Araştırmanın amacı, konaklama işletmelerindeki çalışanların kültürler arası duyarlılık ile iletişim becerileri arasında bir ilişki olup olmadığının irdelenmesidir. Araştırmada yöntem olarak anket tekniğinden yararlanılmıştır. Araştırmanın evrenini Edremit Körfezinde yer alan Turizm İşletme Belgeli oteller, Belediye belgeli otel işletmeleri oluşturmaktadır. Yapılan korelasyon analizinde; iletişim becerilerinden zihinsel, duygusal ve davranışsal boyutları ile kültürler arası duyarlıık boyutlarından etkileşimde sorumluluk boyutunu iletişimde sorumluluk, kültürel farklııklara saygı, iletişimde kendine güvenme, iletişimden hoşlanma ve iletişimde dikkatli olma boyutları arasında pozitif bir ilişki olduğu saptanmıştır.

Anahtar Kelimeler: farklı kültürler, kültürler arası duyarlılık, iletişim becerileri JEL Kodları: M10, M11 


\section{GíRiş}

Etnomerkezci bireyler, kültürlerarası iletişim sürecinde kendi kültürlerini diğerlerinin kültürlerinden üstün görüp diğer kültürü, kendi kültürünün özelliklerine ve kurallarına göre değerlendirdiği için iletişim sürecini olumsuz yönde etkiler. Kültürlerin, belirsizliği azaltma ve sapkın davranış ve düşünceleri tolere edebilme durumlarına atıfta bulunan belirsizlikten sakınma ve kaygı durumu, insanların iletişim kurduğu insanları ve kültürlerini tanımadıkları dolayısıyla nasıl davranacaklarını ve kendilerine nasıl davranılacağını bilmedikleri, riskin ve şüphenin arttığı durumlarda ortaya çıkar. Belirsizlikten sakınma derecesinin yüksek olduğu kültürlerin üyeleri, iletişim sürecinde duygusal, huzursuz, aktif ve saldırgan davranışlar göstererek etkileşimi olumsuz yönde etkiler (Kartari 2001: 87).

Kültürel duyarlılığın bireysel ya da toplumsal düzeyde geliştirilebilmesi kültür şokunun üstesinden gelinmesinde ve kültürel uyum sorunlarının aşılmasında stratejik bir öneme sahiptir. Kültürlerarası iletişim yeterliği, farklı kültürel çevrede yetişmiş insanlar ile etkin ve uygun iletişim kurabilmek anlamına gelmekte ve bilişsel kapasite, toplumsal rol üstlenebilme, kişiler arası iletişim becerisi, dil yeterliği gibi unsurları içermektedir (Kartarı, 2001: 202-207).

Bireyin iletişim ve davranış tarzını, farklı bir kültürel ortamın normlarına uygun hale getirmesi ve kendini etkin bir biçimde ifade edebilmesi kültürlerarası iletişim yeterliğinin temel yapı taşını oluşturmaktadır. Uygun davranış ve iletişim tarzının oluşturulması bilişsel yeterlik ve empati kurma becerisi ile ilgidir. Bireyin kendini etkin bir biçimde ifade edebilmesi için ise öncelikle dil yeterliğinin kazanılması gerekmektedir (Hall\&Hall 1990: 3).

Araştırmamızda, kültürlerararsı duyarlııık ve iletişim becerileri arasındaki ilişki üzerine literatür taraması ve uygulamamız yer almaktadır.

\section{LITERATÜR TARAMASI}

Kültürlerarası duyarlılığın temel göstergesi olarak farklı kültürlere, daha alt kültürlere ve gruplara aidiyet bağlarına yönelik olumlu duygularla yaklaşılması gerekliliğinin savunulmasıdır. Olumlu duygulardan kasıt ise farklııkların önyargısız, stereotipler kullanılmaksızın, etnomerkezcilikten uzak ve yargılanmaksınız değerlendirilmesidir. Bu da anlama, tanıma, onaylama, saygı gösterme, görecelik gibi özelliklerle karakterize olan bir duygu dünyası gerektirmektedir (Bekiroğlu ve Balcı, 2014: 434).

Kültürlerarası duyarlılık, kültürel farklılıkları anlamaya ve keşfetmeye yönelik pozitif duyguların geliştirilebilmesi olarak tanımlanmakta ve bu doğrultuda kültürlerarası yeterliğin desteklenmesi için bireylerin sahip olmaları gereken birtakım özelliklere dikkat çekmektedir. Bu özellikler; özsaygı, özdenetim, açık fikirlilik, empati, etkileşimli ilişki ve önyargılı ya da peşin hükümlü olmama şeklinde sıralanmaktadır (Chen, 1997:23).

Bennett'in (1993) geliştirdiği Kültürlerarası Duyarlılık GelişmeliModeli(The Developmental Model of Intercultural Sensivity, DMIS), kültürlerarası farklılığın birey üzerindeki etkilerini ve farklı kültürlere bakışını betimlemeye yönelik bir kuramdır. Kültürlerarası Duyarlılık Gelişmeli Modeli, bireyin ya da bireylerin başarılı bir kültürel duyarlıı̆ı elde etmek için yapması gereken temel kuralları belirlemektedir. Bu kurallar etnosentrik (etnocentric) (etnomerkezcilik) ve etnorelatif (ethnorelative)(etnogörecilik) olarak iki gruba ayrılırlar. Etnomerkezcilik yani bireyin kendi kültürünü merkez olarak kabul etmesi kendi içinde aşağıdaki gibi ayrımlanmaktadır: reddetme (denial), savunma (defense), küçümseme (minimanization), etnogörecelik yani kendi kültürünü de diğer kültürler ile bağdaştırabilme ise: kabullenme (acceptance), adapte olma (adaptation), bütünleşme (ıntegration) gibi unsurlardan oluşmaktadır.

Bennett ve Hammer (1998)'de bu modeli iki farklı bağlamda incelemektedir. Bu aşamalardan ilki bireyin kendi kültürünü merkez kabul eden etnomerkezcilik (ethnocentrik) uyum ikincisi de bireyin kendi kültürünü diğer kültür bağlamlarında değerlendirdiği etnogörecilik (ethnorelative) uyumdur. Etnomerkezcilik uyumda birey için kendi kültürü temeldir ve var olan diğer kültürler bireyin kültüründen etkilenmektedirler. Dolayısıyla iletişim içinde bulunulan kültürleri kabullenme durumu olmamaktadır.

Kültürlerarası iletişim bağlamında, bireyin, kendi kültürünü dünyanın merkezine koyması, başka kültürleri bu bağlamda değerlendirmesi ve bunun sonucunda diğer kültürü önemsiz görmesi olarak ifade edilen 
etnomerkezcilik (Kartarı, 2001: 185), kültürel uyumun oluşumunda negatif bir durum oluşturmaktadır. Kültürel uyumun oluşması ve sürecin devamı için bireyin etnomerkezci aşamalardan, daha uyuma doğru kabullenmeye doğru etnogöreceli aşamalara doğru ilerlemesi gerekmektedir (Bennett, 1998: 26-30).

Kültürlerarası yeterlik, bireyin amaçlarına ulaşabilmek için çevresine etkin bir şekilde uyum sağlamasını, toplumsal yeterlik, başkalarının duygularını sezebilme, toplumsal rol üstlenme, bilişsel karmaşıklık ve etkileşimi yönetebilmesini; bireylerarası yeterlik, başarılı iletişim yolu ile amaçlara ulaşabilme ve görevleri yerine getirmesini; dil ve iletişim yeterliği, etkileşim sürecinde kullanılan dil ve mesajlarda yeterli olmasını; ilişkisel yeterlik, başarılı bir etkileşim için başkalarıyla daha önceden ilişki kurma yeteneğini anlatmaktadır (Gudykunst\& Hammer, 1988: 47).

Kültürler arası yeterlik, bilgi (bilişsel), tutum (duygusal) ve kişilerarası iletişim becerilerine (davranışsal) dayanmaktadır (Yu, vd., 2001: 80). Bilişsellik kültürel bilinci, duygusalıı kültürel duyarlılığı, davranışsallık kişilerarası iletişim becerisinin etkileşimini ifade etmektedir. Bunlar aynı zamanda endişe, farklılıkların yerine benzerlikleri varsayma, kendi kültürünü diğerlerinden üstün görme faktörlerinin (Jandt, 2001) giderilmesi için gereklidir.

Kültürlerarası iletişim olgusunun, farklı kültür ve aidiyet bağlarının iletişim ve etkileşim örüntülerini ele almasının ötesinde kültürlerarası diyaloğa yönelik bir çağrıyı barındırdığı da söylenebilmektedir. Bu noktada Selçuk'un (2005: 2) da belirttiği gibi; iletişime katılan kişiler, farklı bir kültüre mensup bireylerin iletişim davranışlarını bilmediği sürece ifadeleri, tutum ve davranışları kendi kültürel normlarına ve standartlarına göre anlamlandırmayı tercih edecektir. Bu durum da kültürlerarası etkileşim sürecinde iletişim çatışmalarının yaşanmasını her an için beklenir hale getirmektedir.

\section{VERI VE YÖNTEM}

Araştırmanın evrenini Edremit Körfezinde yer alan turizm işletmelerinde çalışan 448 personele kolayda örnekleme yöntemi ile ulaşılmış ve anketler yüz yüze görüşülerek gerçekleştirilmiştir. Kültürlerarası Duyarlılık Ölçeği (KDÖ) Chen ve Staros'ta tarafından geliştirilen ve kültürler arası duyarlı olmak için gerekli beş duygusal boyutu içeren bir ölçektir. Ölçeğin iletişimde sorumluluk boyutu 1, 11, 13, 21, 22, 23 ve 24. maddelerden, kültürel farklılıklara saygı boyutu 2, 7, 8,16, 18 ve 20. Maddelerden, iletişimde kendine güvenme boyutu 3, 4, 5, 6 ve 10. maddelerinden, iletişimden hoşlanma boyutu 9,12 ve 15 . maddelerinden, iletişimde dikkatli olma boyutu 14, 17 ve 19. maddelerinden oluşmaktadır. Ölçeğin 2, 4, 7, 9, 12,15, 18, 20 ve 22. Maddeleri ters olarak kodlanmaktadır. Kültürel duyarlılı ölçeği, (1) kesinlikle katılmıyorum, (2) katılmıyorum ,(3)kararsızım, (4)katılıyorum ve (5)kesinlikle katılıyorum şeklinde 5'li likert tipi bir yapıya sahiptir.

Chen ve Starosta (2000) tarafından geliştirilen ölçek Bulduk, Tosun ve Ardıç (2011) tarafından Türkçe’ye uyarlanmıştır. Ölçek 5'li likert tipi bir derecelendirmeye sahiptir. Ölçekte 15'i olumlu (kültürler arası duyarlılığı destekleyen) ve 9'u olumsuz (kültürler arası duyarlılığı desteklemeyen) olmak üzere toplam 24 madde bulunmaktadır. Ölçeğin orijinal formu iletişimde sorumluluk ( 7 madde), kültürel farklılıklara saygı (6 madde), iletişimde kendine güvenme ( 5 madde), iletişimden hoşlanma ( 3 madde) ve iletişimde dikkatli olma ( 3 madde) şeklinde adlandırılan 5 boyuttan oluşmaktadır. Orijinal formunda ölçeğinin bütününe ait Cronbach Alpha güvenirlik katsayısı .86 olarak hesaplanmıştır. Ölçeğin Türkçe formu ise orijinal formdan farklı olarak 6 boyutlu bir yapıya sahiptir. Türkçe formunda ölçeğin bütününe ait Cronbach Alpha güvenirlik katsayısı .72 olarak hesaplanmıştır (Bulduk vd., 2011). Ersanlı ve Balcı (1998) tarafından geliştirilen "iletişim Becerileri Envanteri", likert tipi 45 maddeden ve 3 alt boyuttan oluşmaktadır. Bu alt boyutlar madde içeriklerine göre; (zihinsel) bilişsel, (duygusal) duyuşsal ve davranışsal olarak adlandırılmıştır. Her bir boyutu ölçen 15 madde vardır. Zihinsel boyuta giren maddeler 1, 3, 6, 12, 15, 17, 18, 20, 24, 28, 30, 33, 37, 43 ve 45. sorulardır. Duygusal boyuta giren sorular 5, 9, 11, 26, 27, 29, 31, 34, 35, 36, 38, 39, 40, 42, 44 dür. Davranışsal boyutu ölçen soru numaraları ise, 2, 4, 7, 8, 10, 13, 14, 16, 19, 21, 22, 23, 25, 32, 41'dir. Test-tekrar test yöntemi ile yapılan güvenirlik çalışması sonucunda Cronbach's Alfa güvenirlik katsayısı .68, test yarılama yöntemi ile yapılan çalışmada Cronbach's Alfa güvenirlik katsayısı .64 bulunmuştur. Ölçeğin iç tutarlılığınıbelirlemek amacıyla uygulanan Cronbach Alpha katsayısı .72 olarak bulunmuştur. iletişim becerileri envanterinin toplam puanı ile alt ölçekler arasında .001 düzeyinde ve alt boyutların kendi içinde .001 korelasyon bulunmuştur (Ersan ve Balcı, 1998). 


\section{BULGULAR VE TARTIŞMA}

Bu kısımda araştırmanın örneklemi, modeli, hipotezleri, anketin güvenilirliği ve elde edilen verilerin analizi ile hipotez testleri ve elde edilen sonuçların yorumları yer almaktadır.

Tablo 1: Demografik Değişkenlere îlişkin Bulgular

\begin{tabular}{|c|c|c|c|c|c|}
\hline \multicolumn{3}{|c|}{ Medeni Durum } & \multicolumn{3}{|c|}{ Cinsiyet } \\
\hline & FREKANS & YÜZDE & & FREKANS & YÜZDE \\
\hline Evli & 256 & 52,5 & Kadın & 208 & 42,6 \\
\hline Bekar & 232 & 47,5 & Erkek & 280 & 57,4 \\
\hline Total & 488 & 100,0 & Total & 488 & 100,0 \\
\hline \multicolumn{3}{|c|}{ Yaş } & \multicolumn{3}{|c|}{ Çalışma Süresi } \\
\hline 18-25 Yaş Arası & 124 & 25,4 & $1-5 Y_{l}$ & 308 & 63,1 \\
\hline 26-30 Yaş Arası & 136 & 27,9 & 6-10 YII & 137 & 28,1 \\
\hline 31-35 Yaş Arası & 94 & 19,3 & 11-15 Yוl & 32 & 6,6 \\
\hline 36-40 Yaş Arası & 52 & 10,7 & $16-20 Y_{I I}$ & 5 & 1,0 \\
\hline 41-45 Yaş Arası & 52 & 10,7 & 21 YIl ve Üzeri & 6 & 10 \\
\hline 46 Yaş ve Üzeri & 30 & 6,1 & Total & 488 & 100,0 \\
\hline Total & 488 & 100,0 & & & \\
\hline \multicolumn{3}{|c|}{ Çalıştığı Bölüm } & \multicolumn{3}{|c|}{ Eğitim } \\
\hline Komi & 82 & 16,8 & Lise & 311 & 63,7 \\
\hline Anketör & 15 & 3,1 & Üniversite & 150 & 30,7 \\
\hline Resepsiyon & 55 & 11,3 & Master & 10 & 2,0 \\
\hline Satış Danışmanı & 31 & 6,4 & Doktora & 1 &, 2 \\
\hline Güvenlik & 26 & 5,3 & İlk-Orta Okul & 16 & 3,3 \\
\hline Aşçı & 57 & 11,7 & Total & 488 & 100,0 \\
\hline Sağlık & 6 & 1,2 & & & \\
\hline Halkla İlişkiler & 27 & 5,5 & & & \\
\hline $\begin{array}{l}\text { Müdür - Müdür } \\
\text { Yardımcısı }\end{array}$ & 30 & 6,1 & & & \\
\hline Temizlikçi & 106 & 21,7 & & & \\
\hline $\begin{array}{l}\text { Müşteri } \\
\text { Temsilcisi }\end{array}$ & 53 & 10,9 & & & \\
\hline Total & 488 & 100,0 & & & \\
\hline
\end{tabular}

Araştırmaya katılanların demografik bilgileri Tablo 1'de yer almaktadır.

\section{Araştırmanın Hipotezleri}

$\mathbf{H}_{1}$ : Iletişim becerilerinden zihinsel, duygusal ve davranışsal boyut kültürler arası duyarlılık boyutlarından etkileşimde sorumluluk boyutunu arasında pozitif bir ilişki vardır.

$\mathbf{H}_{\mathbf{2}}$ : Iletişim becerilerinden zihinsel, duygusal ve davranışsal boyut kültürler arası duyarlılık boyutlarından kültürel farkıılıklara saygı boyutunu arasında pozitif bir ilişki vardır.

$\mathbf{H}_{3}$ : Illetişim becerilerinden zihinsel, duygusal boyut kültürler arası duyarlılık boyutlarından etkileşimde kendine güvenme boyutunu arasında pozitif bir ilişki vardır.

$\mathbf{H}_{4}$ : İletişim becerileri zihinsel beceriler kültürlerarası duyarlılı boyutlarından etkileşimden hoşlanma boyutu pozitif arasında pozitif bir ilişki vardır.

$\mathbf{H}_{5}$ : İletişim becerilerinden duygusal beceriler kültürlerarası duyarlılık boyutlarından etkileşimde dikkatli olma boyutu arasında pozitif bir ilişki vardır. 
Tablo 2: Güvenilirlik Analizi Sonuçları

\begin{tabular}{|c|c|c|c|}
\hline Boyut Adı & $\begin{array}{c}\text { Boyutların Cronbach } \\
\text { Alfa Katsayıları }\end{array}$ & $\begin{array}{c}\text { Ölçeklerin } \\
\text { Cronbach Alfa } \\
\text { Katsayıları }\end{array}$ & $\begin{array}{lr}\text { Toplam } & \text { Ölçek } \\
\text { Cronbach } & \text { Alfa } \\
\text { Katsayıları } & \\
\end{array}$ \\
\hline KÜLTÜRLER ARASI DUYARLILIK BOYUT & & \multirow{7}{*}{,743 } & \multirow{10}{*}{85,4} \\
\hline Etkileşimde Sorumluluk Boyutu & ,560 & & \\
\hline Kültürel Farklılıklara Saygı Boyutu & ,513 & & \\
\hline Etkileşimde Kendine Güvenme Boyutu & ,574 & & \\
\hline Etkileşimden Hoşlanma Boyutu & ,705 & & \\
\hline Etkileşimde Dikkatli Olma Boyutu & 629 & & \\
\hline ILETIŞiM BECERILERI BOYUTLARI & & & \\
\hline Zihinsel iletişim Becerileri & ,663 & \multirow{3}{*}{,832 } & \\
\hline Duygusal iletişim becerileri & 809 & & \\
\hline Davranışsal iletişim becerileri & ,723 & & \\
\hline
\end{tabular}

Uygulanan anketin güvenilirlik sonuçlarına baktığımızda her bir faktörün yeterli düzeyde güvenilirliğe sahip olduğu görülmektedir. Tablo 2'de görüldüğü gibi anketin genel güvenilirliği 0,832 olarak bulunmuştur.

Tablo 3: Korelasyon Analizi Sonuçları

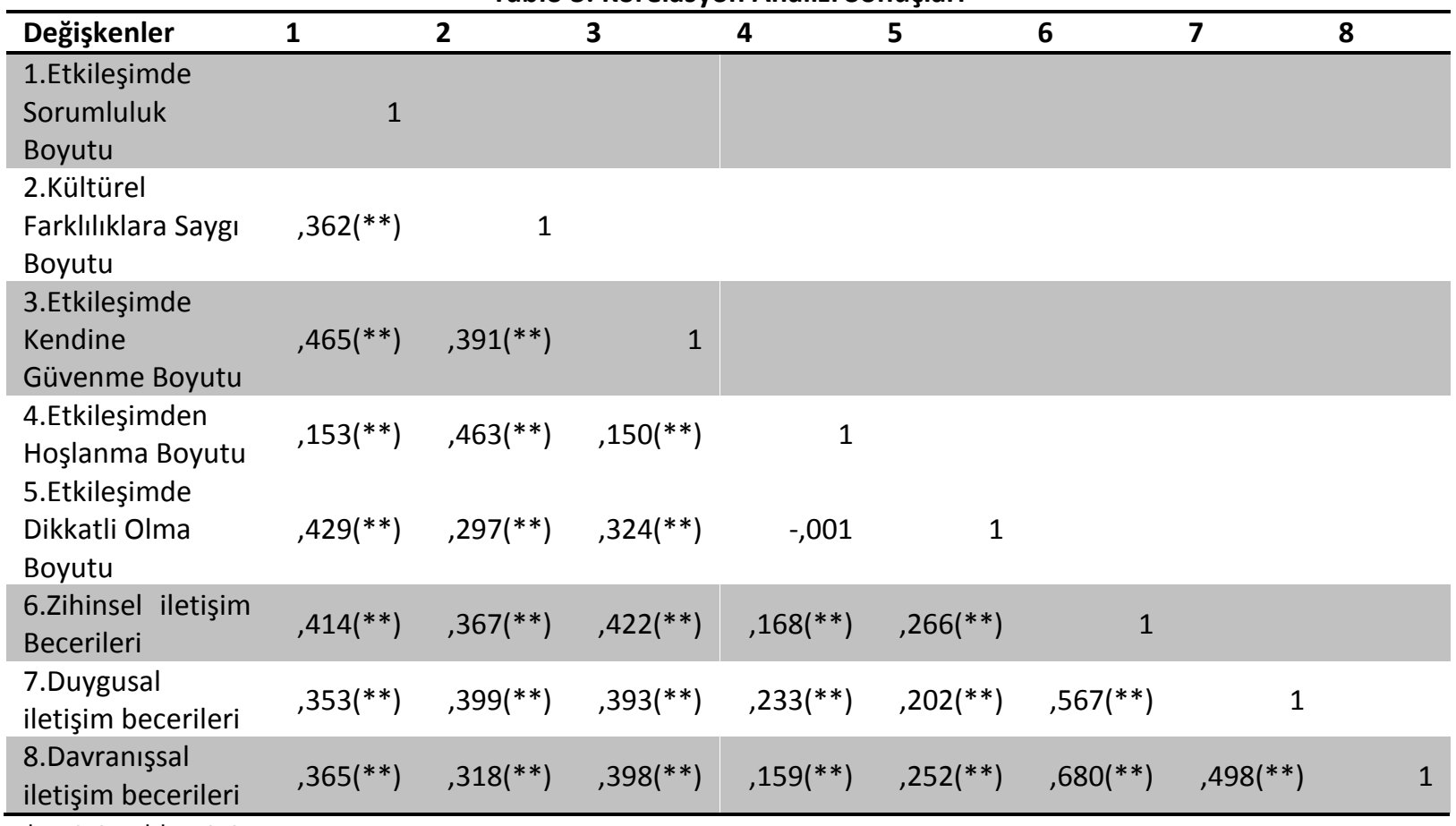

$* p<0,05, * * p<0,01$

Kültürler arası duyarlııı ile iletişim becerileri boyutları arasındaki ilişkiyi görmek maksadıyla korelasyon analizi yapılmıştır. Tablo 3’de görüldüğü gibi boyutlar arasında anlamlı ilişki vardır.

\section{SONUÇ}

Yapılan korelasyon analizinde; İletişim becerilerinden zihinsel, duygusal ve davranışsal boyutları ile kültürler arası duyarlılık boyutlarından etkileşimde sorumluluk boyutunu iletişimde sorumluluk, kültürel farklılıklara saygı, iletişimde kendine güvenme, iletişimden hoşlanma ve iletişimde dikkatli olma boyutları arasında pozitif bir ilişki olduğu saptanmıştır. Yapılan diğer bir çalışmada; üniversite öğrencilerinin duygusal zekâları ile iletişim 
becerileri arasındaki ilişkinin test edilmeye çalışıldığı bu çalışmanın sonuçlarına göre; duygusal zekanın alt boyutları ile iletişim becerisinin alt boyutları arasında korelasyon analizi sonuçlarına göre pozitif yönde anlamlı ilişki olduğu sonucu çıkmıştır (Bozkurtoğlu ve Alparslan, 2011.374). Oyur ve arkadaşları tarafından yapılan çalışmada da; duyguları ifade etme ve iletişim becerileri arasında pozitif yönde anlamlı ilişki bulunmuştur. Ayrıca evli olanların bekâr olanlara göre zihinsel ve duygusal iletişim becerileri farklıdır sonuçlarına ulaşılmıştır (Oyur, vd., 2012: 97).

Günümüzde küreselleşme sadece ticari bir bütünleşme değil aynı zamanda farklı kültürleri bir araya getiren bir dinamizimdir. İletişim teknolojilerinin yoğun olarak kullanılması ve sınırların yok olması nedeniyle oluşan ortak pazarlar çok kültürlü çalışma ortamlarını artırmış göç yollarında farklı kültürel desenleri geliştirmiştir

Farklı kültürlerdeki insanları algıladığımızı davranışlarımızla göstermemiz kültürel duyarlılı̆ın fiziksel unsurudur. Çalışan, farklı kültürlerden kişilerle karşılaştığında beden dilini, konuşma dilini, ifadelerini ve davranışlarını değiştirebiliyorsa, iletişim becerilerini iyi kullanıyor demektir. Bu bağlamda gelecekte çalışanların çok kültürlü ortamlarda başarısında çalışanlarının sahip olduğu iletişim becerileri çok önemli rol oynayacaktır. Kültürlerarası duyarlılık, farklı kültürleri olduğu gibi kabul etmek ve olumlu duygularla yaklaşılması gerekliliğidir. Olumlu duygular, ise farklılıkları olduğu gibi önyargısız, etnomerkezcilikten uzak ve yargılanmaksızın değerlendirebilmektir.

Bu bağlamada gelecekte, kültürlerarası duyarlılık ve kişilik özellikleri, ulusal kültür, özyeterlilik, motivasyon alanlarında çalışmalar yapılması alana ve literatüre katkı açısından önemlidir.

\section{KAYNAKLAR}

Bekiroğlu, O., \& Balcı,Ş., 2014, "kültürlerarası iletişim duyarlılığının izlerini aramak: iletişim fakültesi öğrencileri örneğinde bir araştırma” Türkiyat Araştırmaları Dergisi, ss.429-460.

Bennett, J. M. 1993a, “Cultural Marginality: Identity İssues İn İntercultural Training. In R.M. Paige (Ed.), Education For The İntercultural Experience" Yarmouth, Me: Intercultural Press.

Bennett, Milton J., 1993b, "Towards Ethnorelativism: A Developmental Model Of Intercultural Sensitivity", Paige,M., (Ed) Education Forthe Intercultural Experience, Intercultural Press, Yarmouth.

Bennett, Milton, J., 1998, “Intercultural Communication: A Current Perspective”, Basic Concepts Of Intercultural: Selected Readings, Milton J. Bennett (Ed.), Yarmouth, Me: Intercultural Press, pp.1-24.

Bulduk, S., Tosun, H., Ardıç, E., 2011, "Türkçe Kültürler Arası Duyarlılık Ölçeğinin Hemşirelik Öğrencilerinde Ölçümsel Özellikleri”, Türkiye Klinikleri J. Med. Ethics, 19 (1), ss. 25-31.

Bozkurtoğlu, Çetinkaya Ö. ve Alparslan M. 2011, “Duygusal Zekânın İletişim Becerileri Üzerine Etkisi: Üniversite Öğrencileri Üzerinde Bir Araştırma”, Süleyman Demirel Üniversitesi Iktisadi Ve Idari Bilimler Fakültesi Dergisi, C.16, S.1 s.363-377.

Chen, Guo-Ming Ve William J., Starosta, 2000, "The Development and Validation of the Intercultural Sensitivity Scale" Paper presented at the Annual Meetingof the National Communication Association, Seattle, WA, November 8-12.

Chen, guo-ming, 1997, "A Review of the Concept of Intercultural Sensitivity", Paper Presented at the Biennial Convention Of Pacific and Asian Communication Association, January, Honolulu, Hawaii.

Ersanlı, K. Ve Balcı, S. 1998, “iletişim Becerileri Envanterinin Geliştirilmesi: Geçerlik ve Güvenirlik Çalışması”, Türk Psikolojik Danışma ve Rehberlik Dergisi, 10 (2), ss.7-12.

Gudykunst, W. B., \& Hammer, M. R. 1988, Strangers and hosts: An extension of uncertainty reduction theory to intercultural adaptation. In Y. Y. Kim \& W. B. Gudykunst (Eds.), Cross-cultural adaptation (pp. 106-139). Newbury Park, CA: Sage.

Hall, E. T., Hall, M.R., 1990, “Understanding Cultural Differences”, USA: Intercultural Press, Inc.

Jandt, F.E., 2001, “Intercultural Communication, An Introduction”, California: Sage Publications.

Kartarı, A., 2001, "Farklılıklarla Yaşamak: Kültürlerarası iletişim”, Ankara: Ürün Yayınları.

Oyur E., Mercan N., Saylan O., Buran A., Ç., 2012, "Iş̧ Ortamında Duyguları iffade Etme Ve İletişim Becerileri Üzerine Bir Araştırma” Organizasyon Ve Yönetim Bilimleri Dergisi Cilt 4, Sayı 1, 2012 Issn: 1309 -8039 (Online)

Selçuk, A., 2005, “Kültürlerarası İletişim Açısından Gündelik Illetişim Davranışları”, Selçuk Üniversitesi Sosyal Bilimler Enstitüsü Dergisi, 13, ss. 1-17.

Yu, X., Betty, W., \& Sam, H., 2001, "Intercultural Communication and Mediation: A Framework for Analysing the Intercultural Competence of Chinese Tour Guides", Journal of Vacation Marketing, 8(1), ss.75-84. 